\title{
Targeted primary care-based mental health services for young Australians
}

\section{Elizabeth M Scott BSc(Hons), MB BS, FRANZCP Clinical Director \\ Daniel F Hermens BSc, GDipSci, PhD Senior Research Fellow \\ Nicholas Glozier MB BS, FRANZCP, PhD, Associate Professor of Psychological and Sleep Medicine $e^{1,2}$ \\ Sharon L Naismith MCN, DCN, CCN Director, ', and Associate Professor \\ Adam J Guastella PhD, Principal Research Fellow \\ Ian B Hickie MD, FRANZCP, AM Executive Director, ${ }^{1}$ and Professor of Psychiatry \\ 1 Clinical Research Unit, Brain and Mind Research Institute, Sydney, NSW. \\ 2 Sydney Medical School, University of Sydney, Sydney, NSW. \\ ian.hickie@ sydney.edu.au}

MJA 2012; 196: 136-140 doi: 10.5694/miall.10481 bout $75 \%$ of mental disorders in adults commence before the age of 25 years. ${ }^{1,2}$ The importance of managing anxiety and depression in young people to minimise functional, medical and psychological complications is now widely recognised. ${ }^{3-6}$ Unfortunately, the rapidly accumulating evidence in favour of early intervention has not been matched by substantive changes in patterns of service delivery. ${ }^{2,7-9}$ In 2007 , only $13 \%$ of young men and $31 \%$ of young women with a mental disorder, or alcohol or substance misuse, received any mental health care. ${ }^{10}$ Previous studies of general practice-based services in Australia have highlighted the extent to which the mental health needs of young people, and particularly young men, are not being met. ${ }^{11,12}$ This has led to calls for specific youth-friendly and more easily accessed primary care mental health services. ${ }^{13}$

Consequently, in 2006, the Australian Government launched headspace: the National Youth Mental Health Foundation, with the aim of providing new pathways to mental health care for Australians aged 12-25 years (http://sydney.edu.au/bmri/research/ headspace/index.php). ${ }^{2,14}$

We have collected data on demographic characteristics, diagnostic category, stage of illness, as well as psychosocial and vocational impairment of young people attending two of these new service platforms. Our aim was to determine the extent to which these novel care systems are meeting the objectives of the program.

\section{Methods}

Subjects were consecutive presentations at two youth-specific centres (October 2007 to December 2009) headspace Campbelltown (outer suburban, south-western Sydney) and headspace Central Sydney (inner urban, collocated with the Brain and Mind Research Institute). ${ }^{15}$ Young people (12-25 years of age) may be referred by general practitioners, pae-

Objective: To assess the extent to which youth-specific, mental health care centres engage young people (12-25 years of age) in treatment, and to report the degree of psychological distress, and the diagnostic type, stage of illness, and psychosocial and vocational impairment evident in these young people.

Design and setting: Standardised clinical and self-report assessments of consecutive presentations at two youth-specific centres from October 2007 to December 2009. Both sites are operated by the Brain and Mind Research Institute in Sydney, Australia, as part of headspace: the National Youth Mental Health Foundation mental health care service.

Results: Of 1260 young people assessed, 53\% were male, and the mean (SD) age was 18.1 (3.9) years. Over 40\% of the young people were self-referred, or their assessment was arranged by family or friends, or by other social agencies; $30 \%$ of young people were referred from other primary health providers. Almost $70 \%$ reported high or very high levels of psychological distress. More than $60 \%$ of subjects reported having 2 or more days "unable to function" within the past month, and clinicians rated over $50 \%$ as having at least moderate difficulty in social/occupational functioning. Importantly, $25 \%$ of subjects were receiving income support. Two-thirds of subjects were rated as being at the early stage of an illness, and almost half were diagnosed with anxiety or depressive syndromes.

Conclusions: Targeted youth-specific mental health services, based in primary care settings, are able to engage young Australians, particularly young men, in treatment. Many of these young people report established patterns of psychosocial and vocational impairment.

diatricians, schools, welfare agencies, family or friends, or they may selfrefer.

\section{Measures}

Subjects' clinical information was obtained from brief self-report questionnaires and/or a clinical assessment.

\section{Self-report questionnaires}

On entry to the headspace service, basic demographic data were collected, and standardised questionnaires completed to measure common symptoms, psychosocial functioning, and disability and vocational status. Questionnaires completed included: (i) Kessler-10 questionnaire (K-10); ${ }^{16}$ (ii) Work and Social Adjustment Scale (WSAS); ${ }^{17}$ (iii) Brief Disability Questionnaire (BDQ) ${ }^{18}$ and (iv) Vocational status. Details of the questionnaires are set out in Hamilton et al. ${ }^{15}$

\section{Clinical assessment}

As described previously, ${ }^{13,15}$ assessment at intake was by clinical psychiatrists, clinical psychologists, mental health nurses or GPs with training in mental health. The assessing clinician verified: (i) the reason for referral; (ii) whether the young person was accompanied; and (iii) the clinical stage of illness at presentation for care. ${ }^{19}$ This stage-of-illness rating does not respect traditional diagnostic categories, but instead differentiates young people with non-specific symptoms (Stage 1a) or attenuated syndromes (Stage 1b) from those with a first episode of a major illness (eg, psychosis, mania or severe depression - Stage 2) and those with persistent or recurrent illness (Stage $3+$ ). In other words, Stages $1 \mathrm{a}$ and $1 \mathrm{~b}$ may be considered as subthreshold syndromes (ie, "subsyndromal"), Stage 2 as the first episode of a major illness and Stages $3+$ as later phases of established illness.

Clinicians also rated general functioning using the Social and Occupational Functioning Assessment Scale (SOFAS). ${ }^{20}$

\section{Statistical analysis}

All data were entered into and analysed descriptively using SPSS, version 17 (SPSS Inc, Chicago, Ill, USA). Pearson correlations were used for continuous data. ANOVA or $t$-tests were used for comparisons between groups of subjects, and $\chi^{2}$ tests were 
used to analyse associations between categorical data. Logistic regression was employed to determine whether demographic and/or clinical variables predicted any differences between the two sites. All analyses were twotailed and employed an $\alpha$ level of 0.05 .

As this research was conducted in health service settings (with subjects, clinicians or administrative staff providing information), there were variable rates of missing data.

\section{Ethics approval and consent}

The Human Research Ethics Committee of the University of Sydney approved our study. All subjects gave prospective, written informed consent for their clinical data to be used for research purposes. Parental consent was obtained for subjects under 16 years of age.

\section{Results}

Of the 1260 young people entering our services during the study period, data on referral were available for 1076 subjects: 40.1\% (432/1076) were self-referrals or attendance was arranged by family members or a friend; $30.4 \% \quad(327 / 1076)$ were referred by standard health-referral pathways, such as GPs, other health professionals or contact with public mental health services; and the remainder were referred from 10 different sources, including private psychiatrists, schools, and legal agencies. More than half of the subjects were males $(53.0 \%$; 668) and this pattern was evident across the whole age range.

The levels of self-reported psychological distress (K-10 questionnaire) were high (Box 1), with 69.5\% (681/ 980) scoring in the high to very high range $(\mathrm{K}-10$ total score $>21)$, and $42.0 \%(412 / 980)$ scoring in the very high range $(\mathrm{K}-10$ total score, $>30)$ (Box 2). Ratings of severity of distress increased with age $(r=0.25$; $P<0.001)$.

\section{Common diagnoses and clinical stages}

While common mental health problems such as depression (33.8\%) and anxiety $(14.9 \%)$ were frequently recorded as the primary diagnosis, a

\begin{tabular}{|c|c|c|c|c|c|}
\hline & All subjects & Females (F) & Males (M) & No. of $F / M^{*}$ & $t$-test $(\mathrm{F} \vee \mathrm{M})^{\dagger}$ \\
\hline Age, years, mean (SD) & $18.1(3.9)$ & $18.2(3.8)$ & $18.1(4.0)$ & $592 / 668$ & 0.58 \\
\hline \multicolumn{6}{|l|}{ Disability measures, mean (SD) scores } \\
\hline SOFAS score & $59.7(13.3)$ & $59.5(12.9)$ & $59.8(13.7)$ & $452 / 532$ & -0.42 \\
\hline K-10, total score & $27.4(8.9)$ & $28.9(8.7)$ & $26.0(8.9)$ & $503 / 558$ & $5.36^{\ddagger}$ \\
\hline $\mathrm{K}-10$, total score (high to very high subgroup) & $32.0(6.2)$ & $32.8(6.2)$ & $31.1(6.1)$ & $373 / 365$ & $3.77^{\ddagger}$ \\
\hline WSAS, total score & $18.2(8.2)$ & $18.9(8.1)$ & $17.5(8.3)$ & $342 / 343$ & $2.23^{5}$ \\
\hline BDQ, "days unable to function" in past month & $7.8(9.1)$ & $8.8(9.4)$ & $6.9(8.8)$ & $317 / 327$ & $2.65^{9}$ \\
\hline BDQ, "days in bed" in past month & $3.9(6.6)$ & $5.0(7.4)$ & $2.8(5.5)$ & $322 / 333$ & $4.34^{\ddagger}$ \\
\hline
\end{tabular}

SOFAS = Social and Occupational Functioning Assessment Scale (score range, 1-100; lower scores indicate more severe impairment). K-10 = Kessler-10 questionnaire (a measure of psychological distress - maximum score 50; high scores, 22-29; very high scores, 30-50). WSAS = Work and Social Adjustment Scale (maximum score 40; higher scores indicate greater functional impairment). BDQ = Brief Disability Questionnaire. $*$ Number of subjects with valid data for each measure for females and males. impairment $) . \mathrm{BDQ}=$ Brief Disability Questionnaire. ${ }^{*}$ Number of subjects with valid data for each measure for females and mal
$\dagger t$-statistic, with corresponding significance levels ( $₹ P<0.001 ; \xi P<0.05$; $9<0.01)$ comparing females and males for each variable.

significant proportion of presentations were for other problems associated with impaired attention, antisocial or other socially disruptive behaviours (28.4\%) (Box 3a). Alcohol or substance misuse disorders were recorded as the primary diagnosis in $4.2 \%$ of people. The more severe mood or psychotic disorders were more prevalent in older subjects (Box $2)$. Two-thirds $(69.7 \%, 585 / 839)$ were rated clinically as being in the early phase of illness (ie, Stage 1a or Stage 1b; Box 3a). Consistent with the definitions that are inherent in the staging model, those with depressive, bipolar or psychotic disorders are more likely to be classified as being in Stage 2 or $3+$ (Box 3b).

\section{Disability and impairment ratings}

Among the young people with available data, $24.9 \%$ (224/900) were already receiving financial assistance. Although based on a smaller subset of subjects, the same proportion (175/ 703) reported that they were not working or studying. Importantly, $41.5 \%$ (292/703) were not currently engaged in any form of education, and less than $10 \%(64 / 703)$ were in full-time employment.

Results of the BDQ showed that $63.2 \%(373 / 590)$ of subjects reported 2 or more days "unable to function" in the past month, while over a third $(37.3 \%, 220 / 590)$ reported that they were unable to function for more than a quarter of the past month (Box 2). Nearly half the subjects $(48.1 \%$; 315/ 655) reported spending at least 1 day in bed in the past month because of their psychological problems. Of note, the proportion of subjects with major impairment (more than a week in the past month "unable to function") was twice as high in the severe mood disorder groups (ie, depression or bipolar) as compared with those with an anxiety disorder (Box 2). Similarly, there was an increasing level of impairment reported by subjects at later stages of clinical illness.

Clinicians rated $51.7 \%$ (495/958) of subjects as having significant psychosocial difficulties (SOFAS scores $\leqslant 60$ ) (Box 1 and Box 2). With each increase in level of functional impairment (SOFAS score), there was a corresponding increase in level of psychological distress (K-10 scores: $r=-0.21$; $P<0.001)$. Clinician-rated SOFAS scores were particularly strongly related to clinical stages, with subjects at later stages having much more obvious impaired role function (Box 2).

\section{Differences between male and female subjects}

Males were significantly more likely to have a primary diagnosis of a behavioural or developmental disorder (34.4\% [219/637] of males v 21.4\% [116/542] of females $\left(\chi^{2}[1,1179]=\right.$ 24.2; $P<0.001)$, and two-thirds of those diagnosed with a psychotic disorder were males. However, there were no differences between males and females with regard to clinicianrated levels of disability (Box 1). Compared with males, females selfreported significantly more severe psychological distress (K-10 total, mean [SD]: 28.9 [8.7] v 26.0 [8.9]; $t=$ 5.4; $P<0.001$ ), as well as significantly higher levels of home management/ 
2 Relationships between diagnostic category or clinical stage of illness and age, self-reported work and social disability, selfreported psychological distress, clinician-rated level of functioning, and self-reported days "unable to function"

Mean (SD) [no. of subjects]

\begin{tabular}{|c|c|c|c|c|c|}
\hline & \multicolumn{2}{|c|}{ Mean (SD) [no. of subjects] } & \multicolumn{3}{|c|}{ Percentage [no.] of subjects } \\
\hline & Age & $\begin{array}{l}\text { WSAS } \\
\text { total score }\end{array}$ & $\begin{array}{c}\text { K-10 score, } \\
\text { high to very high }\end{array}$ & $\begin{array}{l}\text { SOFAS score, } \\
\quad \leqslant 60\end{array}$ & $\begin{array}{c}\text { BDQ, } \geqslant 8 \text { days } \\
\text { "unable to function" }\end{array}$ \\
\hline \multicolumn{6}{|c|}{ Diagnostic category } \\
\hline Anxiety & $17.7(4.0)$ [176] & $17.4(7.5)[99]$ & $65.8 \%[96 / 146]$ & $54.4 \%$ [81/149] & $26.6 \%$ [25/94] \\
\hline Depression & 18.4 (3.7) [398] & 20.3 (7.9) [225] & $85.0 \%$ [294/346] & $54.4 \%[174 / 320]$ & $47.4 \%$ [102/215] \\
\hline Bipolar & $19.4(3.5)[68]$ & 20.2 (10.7) [29] & $65.3 \%$ [32/49] & $56.9 \%$ [33/58] & 48.0\% [12/25] \\
\hline Psychosis & 21.0 (3.6) [102] & $18.7(9.5)[30]$ & $63.0 \%$ [46/73] & $71.9 \%$ [46/64] & $40.0 \%$ [10/25] \\
\hline Other* & $17.1(3.8)$ [335] & 15.9 (7.7) [176] & $57.4 \%$ [159/277] & $46.5 \%$ [127/273] & $28.5 \%$ [45/158] \\
\hline Not yet specified & 16.8 (3.1) [100] & 16.6 (8.1) [75] & $60.7 \%$ [54/89] & $36.2 \%$ [34/94] & $35.6 \%$ [26/73] \\
\hline \multicolumn{6}{|l|}{ Clinical stage } \\
\hline Stage la & 16.7 (3.5) [293] & 16.6 (8.1) [189] & $62.2 \%[163 / 262]$ & 28.3\% [81/286] & $31.3 \%$ [57/182] \\
\hline Stage 1b & $17.4(3.4)[292]$ & $19.0(8.2)$ [197] & $72.6 \%$ [188/259] & $51.4 \%$ [148/288] & $35.8 \%$ [67/187] \\
\hline Stage 2 & $18.7(3.2)$ [121] & $23.3(7.0)[55]$ & $82.9 \%$ [68/82] & $87.4 \%$ [104/119] & $54.9 \%$ [28/51] \\
\hline Stage 3+ & 20.3 (3.4) [133] & $20.6(7.5)$ [56] & $84.5 \%$ [71/84] & $77.2 \%$ [95/123] & 40.8\% [20/49] \\
\hline
\end{tabular}

WSAS = Work and Social Adjustment Scale. K-10 = Kessler-10 questionnaire. SOFAS = Social and Occupational Functioning Assessment Scale. BDQ = Brief Disability Questionnaire. Stage la = Mild or non-specific symptoms. Stage lb = Attenuated syndromes. Stage $2=$ First episode of major illness. Stage 3+ = Recurrent or persistent major illness. * Other diagnoses include: attention deficit hyperactivity disorder, conduct disorder, behavioural difficulties, substance misuse, autistic spectrum disorder, personality disorder or eating disorder. ANOVA: (i) diagnostic category by age $(F[5,1173]=22.7 ; P<0.001)$; (ii) diagnostic category by WSAS total score $(\mathrm{F}[5,628]=6.9 ; P<0.001)$; (iii) clinical stage by age $(\mathrm{F}[3,835]=37.3 ; P<0.001)$; and (iv) clinical stage by WSAS total score $(\mathrm{F}[3,493]=11.8, P<0.001] \cdot \chi^{2}$ test for (i) clinical stage by low to moderate $v$ high to very high $\mathrm{K}-10$ score $\left(\chi^{2}[3,687]=23.4 ; P<0.001\right)$; and $(\mathrm{ii})$ clinical stage by low $(\leqslant 60)$ v high $(>60)$ SOFAS score $\left(\chi^{2}[3,816]=155.5 ; P<0.001\right) \cdot \chi^{2}$ test for (i) diagnostic category by low to moderate $(\leqslant 7)$ v high $(\geqslant 8)$ number of days "unable to function" $\left(\chi^{2}[5,590]=20.71 ; P<0.001\right)$; and (ii) clinical stage by low to moderate $(\leqslant 7) \vee$ high ( $\left.\geqslant 8\right)$ number of days "unable to function" $\left(\chi^{2}[4,469]=10.28 ; P<0.05\right)$.

social disability, and more days "unable to function" or "in bed" in the past month (Box 1 gives scores and significance tests).

Similar rates of self-referral or being referred by friends and family were observed for both males and females $(42.4 \%$ [240/566] males $\mathrm{v}$ $37.6 \%$ [192/510] females; $\chi^{2}[1,1076]=$ $2.5 ; P=0.112)$.

\section{Site-specific differences}

The subjects seen at the Campbelltown clinic were significantly younger (mean [SD], 16.7 [3.3] v 19.9 [3.9] years of age; $t=15.6 ; P<0.001)$ than those seen in the Central Sydney clinic. Similarly, the proportion of subjects under the age of 16 years at the outer suburban site was much higher than at the inner city site (52.7\% [379/719] v 19.6\% [106/541]; $\left.\chi^{2}[1,160]=143.0 ; P<0.001\right)$. Notably, there were no significant differences between the sites in terms of levels of disability (ie, K-10, WSAS, BDQ, or SOFAS ratings) or the proportion of females presenting $(48.1 \% \mathrm{v} 46.2 \%$; $\left.\chi^{2}[1,1260]=0.4 ; P=0.507\right)$.

The Campbelltown site tended to have a higher proportion of subjects rated at the earlier "subsyndromal" diagnostic stages, with $40.5 \%$ and $40.3 \%$, respectively, diagnosed as Stage 1a or Stage 1 b, compared with $24.4 \%$ each diagnosed as Stage 1a and Stage $1 \mathrm{~b}$ at the Central Sydney clinic. Conversely, there was a lower proportion of subjects at Stage 2 and Stage $3+$ at the Campbelltown clinic, with $11.1 \%$ and $8.0 \%$, respectively, compared with $20.6 \%$ and $30.6 \%$ at the Central Sydney clinic. The overall $\chi^{2}$ test across sites (Stage $1 \mathrm{v}$ Stage $2+$ ) was highly significant $\left(\chi^{2}[1,839]=92.5 ; P<0.001\right)$.

With regard to the distribution of traditional diagnostic categories, the sites had comparable proportions of subjects diagnosed with depression or anxiety and alcohol or substance misuse disorder. However, the Campbelltown clinic had a higher proportion of subjects with "other" diagnoses (attention deficit hyperactivity disorder, conduct disorder, behavioural difficulties, substance misuse, autistic spectrum disorder, personality disorder or eating disorder) $(32.2 \% \mathrm{~V}$ $\left.23.0 \% ; \chi^{2}[1,1179]=11.7 ; \quad P<0.001\right)$, as well as subjects who were "not yet specified" $\left(10.7 \%\right.$ v $5.3 \% ; \chi^{2}[1$, $1179]=10.5 ; \quad P<0.001)$. By contrast, the Campbelltown clinic had a lower proportion of subjects diagnosed with psychosis $\left(3.8 \%\right.$ v $15.6 \% ; \chi^{2}[1,1179]=$ 51.1; $P<0.001)$ or bipolar disorder $\left(3.8 \%\right.$ v $8.6 \% ; \chi^{2}[1,1179]=2.3 ; P=$ $0.128)$
Given the potential inter-relationships between age at assessment, stage of illness and diagnostic categories, a logistic regression (with site as the criterion variable and age, sex, diagnosis and clinical stage entered as independent variables) revealed that only age and clinical stage reliably predicted site (ie, younger age $(b=-0.20 ; P<0.001)$ and an earlier stage of illness $(b=-0.51$; $P<0.001)$ were associated with the Campbelltown clinic.

\section{Discussion}

We provide the first detailed description of the demographic, diagnostic, stage of illness and disability characteristics of young people presenting to clinical services associated with the new national clinical framework supported by headspace: the National Youth Mental Health Foundation. ${ }^{14}$ Any future reduction in the health and social burden resulting from mental disorders will depend on our capacity to engage and treat effectively those with emerging disorders. ${ }^{1,2}$ These data demonstrate that well designed youth mental health services can directly attract large numbers of young people.

The relatively high rate of self-referral and referrals through family or 
3a Traditional diagnostic categories for mental disorders and clinician-assigned clinical stage

\begin{tabular}{lccc} 
& \multicolumn{3}{c}{ Percentage [no.] of subjects } \\
\cline { 2 - 4 } & Total & Females & Males \\
\hline Diagnostic category* & $n=1179$ & & \\
Anxiety & $14.9 \%[176]$ & $7.4 \%[87]$ & $7.5 \%[89]$ \\
Depression & $33.8 \%[398]$ & $18.4 \%[217]$ & $15.4 \%[181]$ \\
Bipolar & $5.8 \%[68]$ & $3.1 \%[37]$ & $2.6 \%[31]$ \\
Psychosis & $8.7 \%[102]$ & $3.1 \%[36]$ & $5.6 \%[66]$ \\
Other $^{\dagger}$ & $28.4 \%[335]$ & $9.8 \%[116]$ & $18.6 \%[219]$ \\
Not yet specified & $8.5 \%[100]$ & $4.2 \%[49]$ & $4.3 \%[51]$ \\
\hline Clinical stage ${ }^{\ddagger}$ & $n=839$ & & \\
Stage la & $34.9 \%[293]$ & $13.3 \%[112]$ & $21.6 \%[181]$ \\
Stage 1b & $34.8 \%[292]$ & $16.4 \%[138]$ & $18.4 \%[154]$ \\
Stage 2 & $14.4 \%[121]$ & $7.7 \%[65]$ & $6.7 \%[56]$ \\
Stage 3+ & $15.8 \%[133]$ & $8.8 \%[74]$ & $7.0 \%[59]$ \\
\hline
\end{tabular}

Stage $1 \mathrm{a}=$ Mild or non-specific symptoms. Stage $\mathrm{lb}=$ Attenuated syndromes. Stage $2=$ First episode of major illness. Stage 3+ = Recurrent or persistent major illness. *A primary diagnosis was not recorded for 81 subjects. † Other diagnoses include: attention deficit hyperactivity disorder, conduct disorder, behavioural difficulties, substance misuse, autistic spectrum disorder, personality disorder or eating disorder. $¥ 839$ subjects were rated according to a clinical staging model. $\chi^{2}$ test for (i) diagnostic category by $\operatorname{sex}\left(\chi^{2}[5,1179]=36.9 ; P<0.001\right)$; (ii) clinical stage by sex $\left(\chi^{2}[3,839]=15.13 ; P=\right.$

0.002).

3b Distribution of subjects with traditional diagnostic categories by clinicianassigned clinical stage $(n=814)$

Percentage [no.] of subjects

\begin{tabular}{lcccc}
\cline { 2 - 5 } Diagnostic category & Stage la & Stage 1b & Stage 2 & Stage 3+ \\
\hline Anxiety $(n=125)$ & $43.2 \%[54]$ & $30.4 \%[38]$ & $15.2 \%[19]$ & $11.2 \%[14]$ \\
Depression $(n=283)$ & $27.6 \%[78]$ & $38.5 \%[109]$ & $20.1 \%[57]$ & $13.8 \%[39]$ \\
Bipolar $(n=56)$ & $12.5 \%[7]$ & $42.9 \%[24]$ & $16.1 \%[9]$ & $28.6 \%[16]$ \\
Psychosis $(n=61)$ & $8.2 \%[5]$ & $18.0 \%[11]$ & $26.2 \%[16]$ & $47.5 \%[29]$ \\
Other $(n=215) *$ & $45.1 \%[97]$ & $36.7 \%[79]$ & $6.0 \%[13]$ & $12.1 \%[26]$ \\
Not yet specified $(n=74)$ & $56.8 \%[42]$ & $29.7 \%[22]$ & $6.8 \%[5]$ & $6.8 \%[5]$ \\
\hline
\end{tabular}

Stage la $=$ Mild or non-specific symptoms. Stage $1 b=$ Attenuated syndromes. Stage $2=$ First episode of major illness. Stage 3+ = Recurrent or persistent major illness. * Other diagnoses include: attention deficit hyperactivity disorder, conduct disorder, behavioural difficulties, substance misuse, autistic spectrum disorder, personality disorder or eating disorder. $\chi^{2}$ test for diagnostic category by clinical stage $\left(\chi^{2}[15,814]=130.8 ; P<0.001\right)$

friends is remarkable. Unlike many other primary care or specialist mental health services, young men constituted over half of those presenting for care. Although most were in the early phases of illness, disability levels were already pronounced. A quarter of these young people were already receiving financial assistance, with the same fraction completely disconnected from employment or education.

Anxiety and depressive disorders were the most common presentations but the engagement of subjects with other psychological and behavioural difficulties was also notable. Commonly, these young people are excluded from mental health services despite their current need for care or their risk of developing other more severe, persistent or comorbid mental disorders in adult life. ${ }^{1,7,9}$

The willingness of young people to use headspace services challenges existing beliefs about the extent to which young people with mental health problems do not perceive a need for care $^{21}$ or will not attend services that are directly marketed as providing mental health care. By contrast, we have argued that the more pertinent barriers to young people seeking care are practitioner- or service systembased (ie, high cost, youth unfriendly, over-medicalised, over-emphasising physical rather than psychological health care, inaccessible to youth and lacking immediate access to those able to provide relevant psychological and social interventions $\mathrm{s}^{2,8,9,13,15}$ ).

Several characteristics of headspace centres may underpin their potential to engage young people in treatment. These include:

- encouraging others to accompany young people to care (notably parents, family or friends);

- allowing young people to present directly to a youth mental health service;

- removing financial barriers by widespread use of bulk-billing services;

- removing artificial diagnostic barriers (eg, excluding behavioural or personality disturbance);

- removing age barriers (eg, restricting care to those under 18 years);

- providing a "one-stop shop" for general medical and specialised psychological care;

- creating a youth-friendly environment; and

- linking to a national campaign promoting youth mental health services.

Finally, we acknowledge that our study is limited by its cross-sectional nature and by clinical staging being applied by the treating clinicians. Future studies should be longitudinal and undertake consensus ratings.

Acknowledgements: Ian Hickie, Daniel Hermens, and Adam Guastella were supported by a National Health and Medical Research Council Australia Fellowship awarded to lan Hickie (No. 511921). Sharon Naismith was funded by an NHMRC Clinical Research Fellowship (No. 402864). This research was further supported by an NHMRC Program Grant (No. 566529) and a Centres of Clinical Research Excellence Grant (No. 264611), as well as in-kind support from the Clinical Centre, Brain and Mind Research Institute.

Competing interests: Ian Hickie is a director of headspace and the executive director of the Brain and Mind Research Institute. He is also a member of the Federal Minister for Mental Health and Ageing's Mental Health Expert Working Group. Previously (2008-2011), he was a member of the Federal Health Minister's National Advisory Council on Mental Health.

Received 15 Apr 2011, accepted 27 Jul 2011.

1 Kessler RC, Berglund P, Demler O, et al. Lifetime prevalence and age-of-onset distributions of DSM-IV disorders in the national comorbidity survey replication. Arch Gen Psychiatry 2005; 62: 593-602.

2 McGorry PD, Purcell R, Hickie IB, Jorm AF. Investing in youth mental health is a best buy. Med J Aust 2007; 187 (7 Suppl): S5-S7.

3 Bunker SJ, Colquhoun DM, Esler MD, et al. "Stress" and coronary heart disease: psychosocial risk factors. Med J Aust 2003; 178: 272-276.

4 Hall WD, Mant A, Mitchell PB, et al. Association between antidepressant prescribing and suicide in Australia, 1991-2000: trend analysis. BMJ 2003; 326: 1008

5 Hickie IB. Youth mental health: we know where we are and we can now say where we need to go next. Early Interv Psychiatry 2011; 5: 63-69. 
6 Gibbons RD, Hur K, Bhaumik DK, Mann JJ. The relationship between antidepressant prescription rates and rate of early adolescent suicide. Am J Psychiatry 2006; 163: 1898-1904.

7 Hickie IB, McGorry PD. Increased access to evidence-based primary mental health care: will the implementation match the rhetoric? Med J Aust 2007; 187: 100-103.

8 Hickie IB, Groom GL, McGorry PD, et al. Australian mental health reform: time for real outcomes. Med J Aust 2005; 182: 401-406.

9 Burgess PM, Pirkis JE, Slade TN, et al. Service use for mental health problems: findings from the 2007 national survey of mental health and wellbeing. Aust N Z J Psychiatry 2009; 43: 615-623.

10 Hickie IB, Davenport TA, Scott EM, et al. Unmet need for recognition of common mental disorders in Australian general practice. Med J Aust 2001; 175 (2 Suppl): S18-S24.

11 Hickie IB, Luscombe GM, Davenport TA, et al. Perspectives of young people on depression: awareness, experiences, attitudes and treatment preferences. Early Interv Psychiatry 2007; 1: 333-339.

12 Hickie IB, Pirkis JE, Blashki GA, et al. General practitioners' response to depression and anxiety in the Australian community: a preliminary analysis. Med J Aust 2004; 181 (7 Suppl): S15-S20.

13 Scott E, Naismith S, Whitwell B, et al. Delivering youth-specific mental health services: the advantages of a collaborative, multi-disciplinary system. Australas Psychiatry 2009; 17: 189-194.

14 McGorry PD, Tanti C, Stokes R, et al. headspace: Australia's National Youth Mental Health Foundation - where young minds come first. Med J Aust 2007; 187 (7 Suppl): S68-S70.

15 Hamilton BA, Naismith SL, Scott EM, et al. Disability is already pronounced in young people with early stages of affective disorders: data from an early intervention service. J Affect Disord 2011; 131: 84-91.

16 Kessler RC, Andrews G, Colpe LJ, et al. Short screening scales to monitor population prevalences and trends in non-specific psychological distress. Psychol Med 2002; 32: 959-976.
17 Mundt JC, Marks IM, Shear MK, Greist JH. The Work and Social Adjustment Scale: a simple measure of impairment in functioning. $\mathrm{Br} \mathrm{J}$ Psychiatry 2002; 180: 461-464.

18 Von Korff M, Ustun TB, Ormel J, et al. Self-report disability in an international primary care study of psychological illness. J Clin Epidemiol 1996; 49: 297-303.

19 McGorry PD, Hickie IB, Yung AR, et al. Clinica staging of psychiatric disorders: a heuristic framework for choosing earlier, safer and more effective interventions. Aust N Z J Psychiatry 2006; 40: 616-622.

20 Morosini PL, Magliano L, Brambilla L, et al. Development, reliability and acceptability of a new version of the DSM-IV Social and Occupational Functioning Assessment Scale (SOFAS) to assess routine social funtioning. Acta Psychiatr Scand 2000; 101: 323-329.

21 Meadows GN, Burgess PM. Perceived need for mental health care: findings from the 2007 Australian Survey of Mental Health and Wellbeing. Aust N Z J Psychiatry 2009; 43: 624-634. 